\title{
Erratum
}

Z Gerontol Geriat 2012 · [jvn]:[afp]-[alp]

DOI 10.1007/s00391-012-0387-2

Online publiziert: 20 August 2012

(c) Springer-Verlag 2012

R. Piers ${ }^{1} \cdot$ S. Pautex ${ }^{2} \cdot$ V. Curiale ${ }^{3} \cdot$ M. Pfisterer ${ }^{4} \cdot$ M.-C. Van Nes ${ }^{5} \cdot$ L. Rexach ${ }^{6}$. M. Ribbe ${ }^{7} \cdot$ N. Van Den Noortgate $^{1}$

${ }^{1}$ Department of Geriatric Medicine, University Hospital Ghent, Ghent

2 Division of Palliative Medicine, Department of Rehabilitation and Geriatrics, Geneva Medical School and University Hospital, Geneva

${ }^{3}$ Acute Care for Elders Unit, Department of Gerontology, Galliera Hospital, Genoa

${ }^{4}$ Klinik für Geriatrie, Evangelisches Krankenhaus Elisabethenstift, Darmstadt

${ }^{5}$ Department of Geriatric Medicine, CHR de la Citadelle, Liège

${ }^{6}$ Palliative Care Unit, University Hospital Ramón y Cajal, Madrid

${ }^{7}$ VU University Medical Center, Amsterdam

\section{Erratum to: Palliative care for the geriatric patient in Europe. Survey describing the services, policies, legislation, and associations}

\author{
Z Gerontol Geriat 2010 • 43:381-385 \\ http://dx.doi.org/10.1007/s00391-010-0149-y
}

In the original publication, the family name "Curiale" was misspelled.

\section{Corresponding address}

\section{R. Piers}

Department of Geriatric Medicine,

University Hospital Ghent

De Pintelaan 185, 9000 Ghent

Belgium

Ruth.Piers@UGent.be 